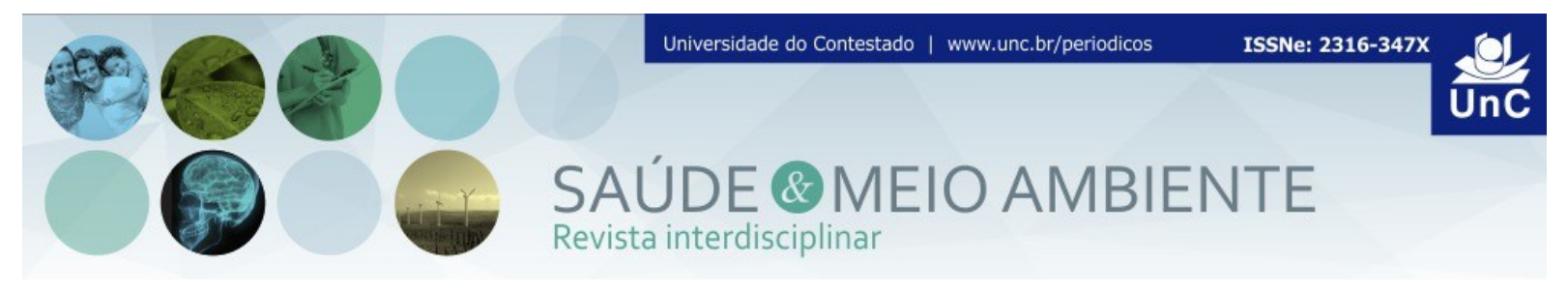

\title{
CICLO E CONTROLE DO Alphitobius diaperinus (COLEOPTERA, TENEBRIONIDAE) NO MUNICÍPIO DE QUITANDINHA, PR
}

\author{
Liriane Rogovski Mendes ${ }^{1}$ \\ Maristela Povaluk ${ }^{2}$
}

\begin{abstract}
RESUMO
A avicultura enfrenta grandes problemas, quanto à infestação de Alphitobius diaperinus, o popular cascudinho, pois estes insetos são trazem grandes perdas para o referido setor, sendo as mais preocupantes as relacionadas à saúde das aves, pois o cascudinho transmite diversas doenças. Além de também danificar a estrutura do aviário. Esta pesquisa teve por finalidade, constatar quais são os métodos para controle do Alphitobius diaperinus, identificando primeiramente o seu processo de desenvolvimento em ambiente avícola, e posteriormente sua classificação, verificando assim os danos que o Alphitobius diaperinus pode causar à saúde das aves. O estudo se baseou na pesquisa, uma semana antes da saída das aves do aviário, que ou a população através de contagens da mesma em pontos técnicos, espalhados por toda extensão do aviário, e após efetuado o controle, após uma semana antes da saída das aves, do aviário, foi efetuada a contagem nos mesmos pontos. Obtendo-se assim o número de indivíduos que indicam a reinfestação. Por meio da comparação dos resultados das contagens, constatou-se resultados, que relatam pontos importantes, como onde há a maior incidência de cascudinhos, a população destes no aviário e a comprovação dos métodos de controle, e a sua eficácia. Os métodos de controle realizados no aviário, foram muito importante, para a saúde das aves, e para o próprio bom rendimento em questões de produção de aves para consumo humano. Desta maneira os resultados de controle apontam para um controle da população, indicando também um melhor rendimento e qualidade, na produção de aves. Os métodos de controle são métodos químicos e mecânicos, sendo os químicos os inseticidas e os mecânicos são procedimentos e atos realizados pelo avicultor, para dificultar o desenvolvimento do cascudinho. Sendo de extrema relevância, a aplicabilidade de todos os métodos possíveis para controle da população, de cascudinhos, para melhorar a carne das aves, que são destinadas para consumo humano.
\end{abstract}

Palavras-chaves: Cascudinho. Avicultura. Aves.

\footnotetext{
${ }^{1}$ Acadêmica do Curso de Ciências Biológicas da Universidade do Contestado. Campus Mafra. Santa Catarina. Brasil. E-mail: lirimendes@hotmail.com

${ }^{2}$ Doutora em Educação pela Pontifícia Universidade Católica do Paraná (2013). Mestre em Educação

Ensino Superior pela Fundação Universidade Regional de Blumenau (1997), Mestre em

Psicopedagogia pela Universidade da Região de Jaraguá Universidad de La Havana (2000).

Universidade do Contestado. Santa Catarina. Brasil. E-mail: maristela@unc.br
} 


\title{
CYCLE AND CONTROL IF Alphitobius Diaperinus (COLEOPTERA, TENEBRIONIDAE) IN QUITANDINHA CITY
}

\begin{abstract}
The poultry industry faces major problems, as the infestation Alphitobius diaperinus, the popular mealworm because these insects are bringing huge losses for that industry, the most concern related to the health of birds, as the mealworm transmit various diseases. It would also damage the structure of the aviary. This research was intended, observe what are the methods to control Alphitobius diaperinus, first identifying your development process in poultry environment, and then their classification, thus verifying the damage that can cause to the health of birds. The study was based on research, a week before the departure of the birds in the aviary, or to the population through the same scores on technical points scattered throughout extension of the aviary, and after conducted control after a week before the exit of birds, the aviary, the count was performed in the same spots. Thereby obtaining the number of individuals indicating reinfestation. By comparing the results of scores, it was found results, which report important points, such as where there is a higher incidence of catfishes, the population of these in the aviary and proof of control methods and their effectiveness. Control methods carried out in poultry, were very important to the health of birds, and the very good performance in poultry production issues for human consumption. Thus the results of control point to control the population, also indicating a better yield and quality in poultry production. Control methods are chemical and mechanical methods, with chemical pesticides and mechanics are procedures and actions undertaken by the farmer, to hinder the development of the mealworm. Being extremely important, the applicability of all possible methods for population control of catfishes to improve the meat of poultry, which are intended for human consumption.
\end{abstract}

Keywords: Mealworm. Poultry. Birds.

\section{INTRODUÇÃO}

Atualmente os produtores de frangos enfrentam diversos problemas causados por pragas como os besouros cascudinhos Alphitobius diaperinus, que é comum em aviários e se comporta como uma importante praga da avicultura. O cascudinho possui características comportamentais e hábitos biológicos que dificultam seu controle, e também é considerado um vetor de agentes patogênicos.

O cascudinho Alphitobius diaperinus, originário da África, quando habita granjas avícolas traz consigo diversos problemas para o sistema, alimentando-se das carcaças das aves, das fezes e da ração de aves, este tem seu ciclo biológico que se completa em 55 dias, em temperatura de $27^{\circ} \mathrm{C}$. 
Com o crescimento da população avícola resultado da alta demanda do mercado, acarreta um aumento da criação de aves em confinamento, o que resulta em um aumento da densidade das aves dentro do galpão. Em função desse aspecto, há um incremento da umidade da cama aviária, proveniente tanto das excretas das aves, como da água dos bebedouros, que favorece o crescimento de populações do coleóptero Alphitobius diaperinus, popularmente conhecido como cascudinho. O contato direto do inseto com a cama das aves, assim como a alimentação a partir de aves moribundas e mortas, faz do A.diaperinus um veiculador de diversos patógenos, sendo destacados bactérias, protozoários e vírus que causam imunossupressão nas aves.

Além da relação com os patógenos, os cascudinhos podem provocar danos nas instalações avícolas, pois na fase larval escavam túneis no material isolante para empoparem e destruírem a proteção de poliuretano usada para isolamento térmico dos galpões em países de clima frio, a qual precisa ser trocada a cada dois ou três anos. Outro fator prejudicial às aves é a substituição da ração balanceada por larvas e adultos do coleóptero, uma vez que afeta o ganho de peso, principalmente, das mais jovens. Frente ao exposto, a presença do cascudinho em instalações avícolas torna-se um problema, tanto sanitário, como financeiro. $O$ controle do $A$. diaperinus é considerado difícil e inseticidas químicos são comumente utilizados em aviários, mas apresentam desvantagens, pois deixam resíduos na carcaça, bem como no meio ambiente. A presença de alta quantidade de matéria orgânica nos aviários provoca a diminuição da efetividade dos inseticidas químicos. Vários estudos vêm sendo desenvolvidos na busca de alternativas, para o controle do $A$. diaperinus, devido ao seu difícil controle.

O cascudinho, Alphitobius diaperinus, representante da ordem coleóptera, é um inseto cosmopolita, que se espalha em todo o aviário, uma importante praga da avicultura mundial, isto devido a suas características comportamentais e hábitos biológicos que dificultam seu controle, mas existem controles químicos e mecânicos. Tanto as larvas como adultos são frequentemente encontrados na cama de aviários, pois retiram dela todo alimento necessário para sua sobrevivência, como: adubo, ração, aves mortas e moribundas, assim encontrando um ótimo ambiente para ampliar sua população.

O crescimento da produção avícola provocado pela alta demanda do mercado acarreta um aumento da criação de aves em confinamento, o que resulta em um aumento da densidade das aves dentro do galpão. Em função disso, há um incremento da umidade da cama aviária, proveniente tanto das excretas das aves, como da água dos bebedouros, que favorece o crescimento de populações do coleóptero Alphitobius diaperinus, popularmente conhecido como cascudinho (JAPP, 2010, p.1668).

Estes insetos tem sido responsáveis por grandes prejuízos econômicos na avicultura e são encontrados abundantemente nas instalações avícolas. O cascudinho adaptou-se muito bem as condições que o aviário oferece e os principais alimentos deste besouro são a ração, fezes e animais mortos.

O inseto $A$. diaperinuss e tornou bastante comum em criações de aves de corte devido ao sistema de produção utilizado que é mais do que acolhedor ao 
cascudinho, pois as aves são criadas sobre o piso (chão batido ou cimento) coberto com cepilho, misturado às fezes, ração e água. Estes fatores aliados às elevadas temperaturas e umidade no interior dos galpões de criação, favorecem ainda mais o desenvolvimento deste inseto que tende a aumentar sua população constantemente nestas condições.

O cascudinho Alphitobius diaperinus pertencente à ordem coleóptera, está sendo a maior ordem de insetos, tendo sua distribuição em quase todos os lugares. Uma das caracteristicas dos coleopteros é a estrutura da asa.

\begin{abstract}
A maioria dos besouros possui 4 asas, com o par anterior espessado, coriáceo ou duro e brilhante e usualmente tocando-se em uma linha reta ao longo da porção mediana do dorso, cobrindo as asas posteriores (dai o nome da ordem). As asas posteriores são membranosas, geralmente mais longas que as asas anteriores e, quando em repouso dobram-se sob estas. As asas anteriores dos besouros são chamadas élitros (sincular, élitro). Os élitros normalmente servem apenas como estojo de proteção; as asas posteriores são as únicas ordinariamente usadas para o vôo (BORROR et al, 1969, p. 192).
\end{abstract}

As peças bucas na ordem coleoptera são do tipo mastigador e com mandíbulas bem desenvolvidas. Os besouros desta ordem possuem hábito alimentar e habitat bem variado, pois se alimentam de todos os tipos de mateirais vegetais e animais. Esta ordem possui pernas modificadas de várias formas, na maioria das vezes com garras e estruturas adesivas. Nos estágios imaturos (larvas) terrestres ou aquáticos, com cápsula cefálica esclerotizada e em geral possuem pernas torácicas com cinco artículos, sem possuírem brânquias abdominais ou glândulas de seda no lábio.

A família Tenebriónidae constitui um grande e variado grupo, em sua maioria, preta ou castanha. Muitos são pretos e lisos e exibem manchas vermelhas nos élitros que lembram os besouros do solo. Os besouros deste genêro medem de 13 $\mathrm{mm}$ a $17 \mathrm{~mm}$ de comprimento e diversas destas espécies são pragas comuns de grãos armazenados de importância agrícola e são muito destrutivoros. Constituem a quinta maior família de besouros.

O Alphitobius diaperinus, conhecido popularmente como Cascudinho pertencente ao Filo Artrópode, Classe Inseto, Ordem Coleóptera e Família Tenebrionidae. Este inseto cascudinho é considerado uma praga dos grãos armazenados, se adaptou aos galpões de aves e que a cada dia traz mais prejuizos aos aviários.

Devido ao cascudinho ser uma praga na avicultura cada vez mais se procuram métodos alternativos para controle da população do besouro. Os estudos, quanto ao comportamento e resistência do besouro, são muito importantes para se chegar à uma forma de controle.

$\mathrm{Na}$ ordem do besouro cascudinho, a duração do ciclo de vida varia de quatro gerações por ano, apresentando também até uma geração em vários anos; sendo que a maioria das espécies apresenta uma geração por ano. Os besouros desta ordem podem passar o inverno em qualquer um dos estágios de vida, isto 
dependendo da espécie. Sendo comum que passem o inverno como larvas parcialmente desenvolvidas. Muitos outros passam como pupas em câmaras no solo, na madeira ou em qualquer outro local protegido, também há outros que passam o inverno como adultos; Sendo muito poucas as espécies que passam o inverno no estágio de ovo. Devido ao cascudinho apresentar-se resistente, torna-se uma praga de difícil controle no aviário.

\begin{abstract}
A indústria avícola está em contínua expansão no Brasil, conquistando espaços cada vez maiores no mercado externo. Alphitobius diaperinus (Panzer), conhecido como cascudinho ou "lesser mealworm", coloniza o substrato encontrado em granjas avícolas, desenvolvendo altas populações, causando problemas sanitários e econômicos, afetando a saúde e o crescimento das aves e atuando também como transmissor de doenças (CHERNAKI; ALMEIDA, 2001, p.365).
\end{abstract}

O cascudinho em seu hábito de vida, quando associado granjas avícolas, alimenta-se de aves moribundas, das carcaças, das fezes e da ração de aves. Assim esta população encontra um ambiente propicio para aumento de sua população, pois possui alimento em todo o sistema do aviário.

O ciclo biológico do cascudinho Alphitobius diaperinusse completa em 55 dias, este em temperatura de $27^{\circ} \mathrm{C}$. São postos pela fêmea centenas de ovos, em grupos, na cama do aviário ou no esterco durante a vida desta. A eclosão ocorre em cerca de 3 a 10 dias, em temperaturas de 18 a $40^{\circ} \mathrm{C}$ ".

Após cinco dias da postura dos ovos, eclode de cada ovo uma larva esbranquiçada, com $1,5 \mathrm{~mm}$ de comprimento. A fase larval estende-se por 38 dias, quando assim os imaturos atingem o tamanho de $13,8 \mathrm{~mm}$ de comprimento e coloração marrom escura. As larvas passam por até 11 estágios de desenvolvimento estes estágios são fundamentais e muito importantes para seu desenvolvimento. Assim prosseguindo a fase larval, estes sofrem ecdise e empupam por cinco dias. Após este período surge apupa de coloração esbranquiçada, e sua forma lembra a do adulto, podendo-se notar os contornos de olhos, asas e outras características. $O$ adulto emerge entre 4 a 14 dias, este apresentando coloração castanha a preta, dependendo da espécie pode viver mais de um ano. Para recomeço do ciclo, as fêmeas adultas iniciam a postura entre 6 a 10 dias após o acasalamento.

Segundo Salin et al. citado por Japp et al. (2010, p. 1669):

A estrutura espacial dessa população de insetos no solo, em uma granja avícola, apresenta alta heterogeneidade; as larvas de últimos estágios de vida, pupas e adultos, são localizadas no solo, cerca de $10 \mathrm{~cm}$ de profundidade, preferencialmente abaixo dos comedouros, onde o substrato apresenta-se denso, compactado e com umidade baixa. Esses insetos, em reduzidas temperaturas e/ou situações de estresse, não realizam diapausa, como os demais insetos, migrando em movimentos verticais para baixo em direção ao solo.

O cascudinho apresenta seu processo de desenvolvimento no ambiente avícola, com o ovo, a fase larval, a pupa e fase adulta. Suas fases estão relacionadas fortemente com a temperatura do aviário, fator determinante para sua sobrevivência. 
É importante salientar a contribuição de Chernaki; Almeida citado por Japp (2010, p. 1669):

\begin{abstract}
Foi observado que a $22^{\circ} \mathrm{C}$ o tempo de desenvolvimento de suas fases é maior, porém a sobrevivência é baixa, e que a temperatura de $31^{\circ} \mathrm{C}$ foi considerada a mais adequada para o desenvolvimento das fases imaturas, com alta sobrevivência. Temperaturas baixas (inferiores a $16,5^{\circ} \mathrm{C}$ ) podem contribuir de maneira eficiente para o controle desses insetos, uma vez que não ocorre o desenvolvimento das fases imaturas, o que leva a uma diminuição da população.
\end{abstract}

Este desenvolvimento apresenta diversas fases que são muito importantes para o adulto. Este inseto encontrou um ótimo lugar para seu desenvolvimento na cama do aviário, encontrando abrigo, alimento variado e outras condições para seu desenvolvimento como a temperatura, assim tornando-se uma preocupação para os avicultores.

O controle atualmente apresenta inúmeras dificuldades, pois seus inimigos naturais são muito pouco conhecidos e até o momento não foi descoberto um método de controle eficiente e seguro. O método de controle é importante para proteger as aves do principal problema, a transmissão de doenças. Temos dois métodos de controle: o método mecânico e o químico.

Paiva (2000, p. 23) efetua a sua contribuição salientando que: "As medidas de controle têm por objetivo proteger as aves do principal problema ocasionado por essas pragas: a transmissão de doenças".

No caso do cascudinho, o controle mecânico, que é realizado no inverno, na saída do lote e com atos simples, como, manter abertas as cortinas para matar as larvas pelo frio. Outro ato importante é o amontoamento da cama no primeiro dia após a saída do lote de aves e a manutenção da cama coberta com lona plástica durante todo vazio sanitário permite um aumento de temperatura e a liberação de amônia. Esse procedimento auxilia no controle da coccidiose, que o cascudinho é vetor, e também auxilia na diminuição da população de cascudinhos no aviário. Pode-se também prolongar esse período estendendo somente parte da cama para o recebimento dos pintinhos do próximo lote, deixando o restante ainda coberto com Iona plástica, estendendo-a na véspera da liberação dos pintinhos do cercado para obter melhor controle do cascudinho.

\title{
METODOLOGIA
}

A presente pesquisa foi efetuada através de pesquisa bibliográfica, pesquisa de campo; por meio de verificação "in loco" por meio de fichas de observação e registros fotográficos e experimental, tendo como base o método qualitativo e quantitativo. A pesquisa foi efetuada em uma granja avícola localizada no município de Quitandinha, PR em propriedade rural, sendo que Figura 1, enfatiza o local onde foi efetuada a presente pesquisa. 
Figura 1 - Localização Quitandinha, PR

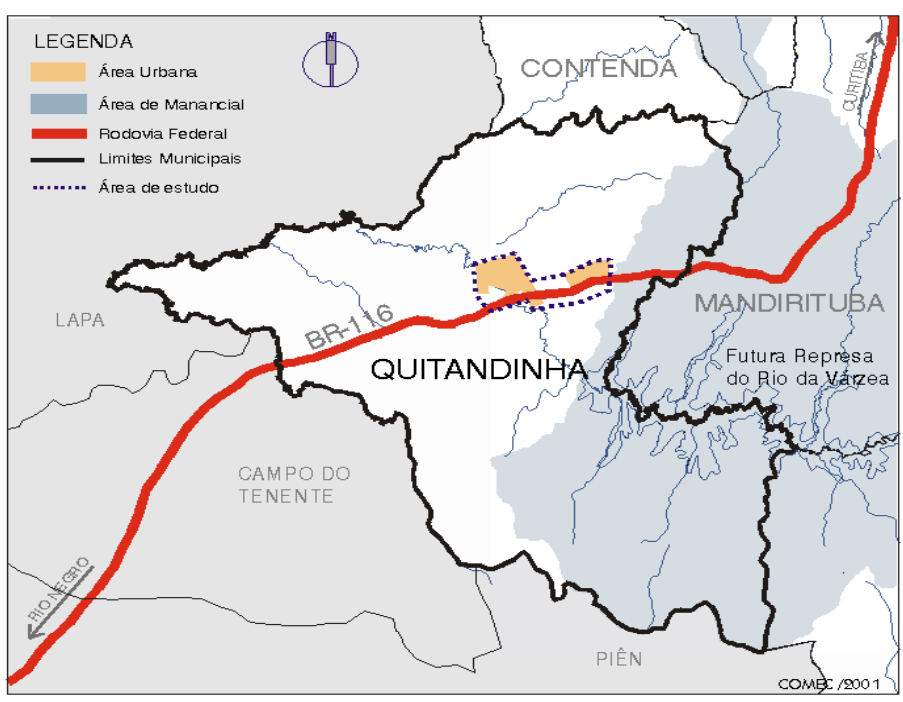

Fonte: COMEC (2011)

Primeiramente foi efetuado contato com o proprietário do aviário para solicitação de autorização para efetuar a pesquisa. Inicialmente os dados foram anotados em fichas de observação, para coleta de dados e também foram realizados registros fotográficos da área de estudo.

Posteriormente, o aviário foi dividido ao meio e considerei os pilares centrais, sendo que cada uma das metades é novamente dividida igualmente e os pilares centrais constituem os locais de amostragem.

Sendo que uma semana antes da saída do lote de frangos, foi definida a amostragem com 14 pontos no aviário para estudo, sendo seis conjuntamente aos pilares, quatro próximo às muretas e quatro sob os comedouros. Em cada ponto, coletou-se uma amostra da cama de $30 \times 30 \mathrm{~cm}$, em total profundidade até o solo, que foi peneirada (uma peneira de malha grossa acoplada em outra de malha fina) sobre uma lona plástica branca, para a contagem apenas do número de adultos.

Após o processo de contagem de insetos adultos nos pontos de estudo no aviário, foi efetuado o acompanhamento do tratamento químico para controle do cascudinho, efetuado com lona mento da cama e aplicado o tratamento químico, sendo que o processo foi observado com auxílio de fotografias e fichas de observação.

Na sequência repete-se a amostragem, uma semana antes da saída desse primeiro lote alojado, de forma que os dados obtidos na primeira avaliação corresponderão à totalidade da população (100\%) e a avaliação subsequente indicará o percentual de re-infestação do aviário e consequentemente, a eficiência da estratégia de controle de cascudinho.

Após efetuar novamente a contagem de insetos adultos nos pontos de estudo no aviário, para verificar a eficácia do controle, foi realizado a análise dos dados 
obtidos, e também para complementação de estudo foi realizado uma entrevista com o veterinário da referida granja.

\title{
RESULTADOS E DISCUSSÕES
}

Os métodos de controle são muito importantes, pois devido as condições que o aviário oferece, como alimento e abrigo para o cascudinho, são condições apropriadas para o aumento desta população e se torna evidente a necessidade do controle pelos proprietários dos aviários.

"Na avaliação de estratégias de controle do cascudinho em aviários de frango de corte, são igualmente verificadas variações no método empregado para a estimativa populacional" (GODINHO, 2009, p.108).

Quanto ao controle químico este é realizado após a saída das aves no final do lote, com a retirada da cama é necessário aplicar o inseticida nas paredes, pilares, vigas, travessas e tesouras, além de muretas (por dentro e por fora), beirais, caixas de ração. Mesmo que não possa ser retirada a cama, é importante abrir a cama sob os comedouro e pulverizar o piso onde estão os insetos, também abrir a cama ao redor dos pilares e muretas para pulverizar o piso para efetuar um melhor controle.

Nos casos de controle químico do cascudinho, realizados nos ambientes avícolas, principalmente à base de piretróides e organofosforados, pode levar algumas desvantagens, como o surgimento de populações resistentes, contaminação do ambiente e das aves e eliminação dos inimigos naturais, pois abrange todo ambiente avícola, também desfavorecido pelo curto ciclo de vida e o comportamento críptico do inseto, juntamente com a presença contínua das aves, o que favorecem as reinfestações.

\begin{abstract}
Os químicos usados no controle são de difícil aplicação em razão dos ambientes habitados por esses insetos, tais como o solo, os locais com grande quantidade de matéria orgânica (excreta, ração e cepilho), entre as cortinas e as frestas dos galpões, o que inviabiliza a ação dos produtos. Normalmente, resultados pouco expressivos estão relacionados à inadequada aplicação do produto (ARENDS, 1987; JAPP, 2010, et al. p. 1670).
\end{abstract}

Os métodos de controle, utilizados atualmente não são totalmente eficazes, devido estes aspectos, cresce a necessidade de alternativas para controlar o problema. As pesquisas nesta área, estão tendo um bom desenvolvimento, e como um ponto positivo, pela a necessidade de novas alternativas para controle.

Os danos à saúde das aves são vários, e são danos considerados graves e de suma importância que se acarretem estudos na área, mas o cascudinho não acarreta somente doenças as aves, mas também aos humanos. Segundo Schrockenstein et al. citado por Japp (2010, p. 1670): "Estudos atestam que pesquisadores, após dois anos de estudos e manipulação dessa espécie, 
começaram a apresentar sintomas alérgicos, urticárias, angioedema, asma e conjuntivite".

Quando os cascudinhos se alimentam de animais mortos e moribundos, aumentam a possibilidade de atuarem como vetores mecânicos de agentes patogênicos e mais ainda, por se alimentarem também da pele de animais fracos e doentes aumentam, a debilidade dessas aves, o que é prejudicial.

É importante ressaltar, que um grande problema em relação ao cascudinho, é que este é ingerido pelas aves, no lugar da ração balanceada, assim reduzindo a ingestão de nutrientes que são necessários as aves e afetando o desenvolvimento destas.

Os cascudinhos presentes nos aviários, tanto adultos ou larvas, perfuram a pele das aves, se alimentando do exsudato sanguíneo e também provocando ferimento no trato digestivo (papo e moela), podendo levar à morte pintinhos recémeclodidos ou confinados em pequenos espaços, causando mais um prejuízo a avicultura. Outro fator importante é que durante o processamento no abatedouro, quando se faz a extração do papo e da moela pode-se contaminar a carcaça da ave.

Segundo Vittori et al. citado por Hemura et al. (2008, p. 430):“Este inseto é também um reservatório e potencial transmissor de protozoários, platelmintos, fungos, bactérias, vírus patogênicos às aves, incluindo coronavírus". Todos os danos causados pelo cascudinho refletem em um grande sistema, onde primeiro atingem as aves, posteriormente vindo a atingir a saúde das pessoas e refletindo também em um grande sistema econômico. Mas o que mais preocupa é a grande quantidade de agentes patógenos, pois a espécie é vetora, e a gravidade destas patogenias no aviário preocupa os avicultores.

Axtell e Arends, citado por Japp (2010, p. 1669), efetuam a sua contribuição, solicitando que: "O contato direto do inseto com a cama das aves, assim como se alimentar de aves moribundas e mortas, faz do $A$. diaperinus um veiculador de diversos patógenos aviários."

A praga do besouro cascudinho traz muitos incômodos para a saúde das aves, pode servir como fonte de infecção para Campylobacter spp., e também é vetora de patógenos em aviários, tendo sido isolados dos insetos diversos vírus, estes vírus sendo de doenças bem incomodas para o sistema da avicultura, como o vírus da doença de Gumboro; enterobactérias Proteus vulgaris, Klebsiellap neumoniae, Enterobacter spp., Escherichia coli,e o protozoário Eimeria sp., este último sendo o causador da coccidiose intestinal em aves, e também podem transmitir: aspergilose, bacterioses como E. coli, Salmonella spp. Bacillus, Streptococcu ssp., viroses tais como leucose, Marek, New Castle, Reovirus, Rotavirus, Enterovirus, Parasitoses como as Hymenolepis carioca, H. cantiana, Choanotaenia infundibulum Raillietina cesticillus, Heterakis gallinae- este transmissor do protozoário Histomonas meliagridis causador da doença "cabeça negra dos perus", entre outras, os incômodos que este besouro acarreta são de amplas dimensões. 
Além de danos à saúde, os cascudinhos podem provocar danos nas instalações avícolas quando danificam a proteção de poliuretano usada para isolamento térmico dos galpões de aviários, em países de clima frio.

Com relação ao método de avaliação de população de cascudinho (Alphitobius diaperinus) em aviários de frango de corte, a técnica foi baseada na coleta de amostras da cama do aviário em 14 pontos previamente determinados, seguido da contagem de adultos de alphitobius diaperinus, e posterior comparação percentual dos valores obtidos antes e após a adoção da estratégia de controle. a técnica permite avaliar a população de todo o aviário.

Para manter o controle da população de Cascudinhos, é importante a implementação correta de métodos de controle.

Segundo Silveira Neto et al. citado por Godinho et al. (2009, p.107):

\begin{abstract}
Pode-se expressar populacionalmente um animal em termos absolutos (número de indivíduos em uma determinada unidade de área) ou relativos (indivíduos em uma área desconhecida). A segunda forma é obtida com base em dados coletados em armadilhas e é importante nas comparações populacionais no tempo e no espaço (como na avaliação da eficiência de uma estratégia de controle).
\end{abstract}

Existem poucos trabalhos realizados no Brasil sobre o Cascudinho Alphitobius diaperinus, e a maioria dos trabalhos foram realizados em aviários de galinhas poedeiras. A dificuldade do estudo populacional deste inseto é justamente a elevada população.

Godinho (2009, p. 108) efetua a sua contribuição salientando que:

Recentemente, visando-se avaliar a eficiência do controle químico de cascudinho em aviários de frango de corte, foi desenvolvida uma forma que se baseia na amostragem da cama em pontos fixos distribuídos no aviário, priorizando-se os locais de maior concentração de insetos (sob comedouros, junto aos pilares e muretas).

Na necessidade de se verificar a eficiência do controle químico do cascudinho em aviários de frango de corte, foi desenvolvida uma técnica que avalia a população de cascudinhos. Esta técnica se baseia na retirada de uma amostragem da cama do aviário em pontos fixos distribuídos na área do aviário, primeiramente priorizando se os locais de maior concentração de cascudinhos, estes sendo sob comedouros, junto aos pilares e muretas. As áreas de escolhas para estudo são acompanhadas sistematicamente em intervalos de tempo, sendo a descrição do método o próprio objetivo do trabalho. A técnica se resume, primeiramente na escolha dos 14 pontos de estudo no aviário, prosseguindo a técnica, é realizado uma semana antes da data da saída do lote de aves alojadas, a avaliação populacional de cascudinho nos aviários, esta avaliação realizada nos 14 pontos distintos, nestes pontos seis junto aos pilares, quatro junto às muretas e quatro sob os comedouros. Primeiramente, divide-se o aviário ao meio e consideram-se os pilares centrais. Posteriormente cada uma das metades é novamente dividida igualmente e os pilares centrais constituem os locais de amostragem. 
Em relação às muretas e comedouros, são avaliados aqueles que estão localizados nas linhas que dividem o aviário em três partes iguais, porém são desconsiderados os comedouros mais próximos às muretas. Após a escolha dos pontos, em cada um destes, coleta-se uma amostra da cama, medindo $30 \times 30 \mathrm{~cm}$, em total profundidade até o solo, peneirada, utilizando-se de uma peneira de malha grossa acoplada em outra de malha fina. A peneiração é realizada sobre uma lona plástica branca para a contagem apenas do número de adultos.

Após a avaliação do número de cascudinhos adultos nos pontos de estudo e a saída das aves, a cama usada é removida e as práticas de limpeza e higienização são adotadas, ou a cama usada é tratada com lona mento e produtos para controle do cascudinho. Posteriormente, à avaliação do número de cascudinhos, faz-se a aplicação da tática de controle e distribui-se a cama nova e aloja-se o novo lote de aves.

Figura 2 - Mapa com os pontos de estudo

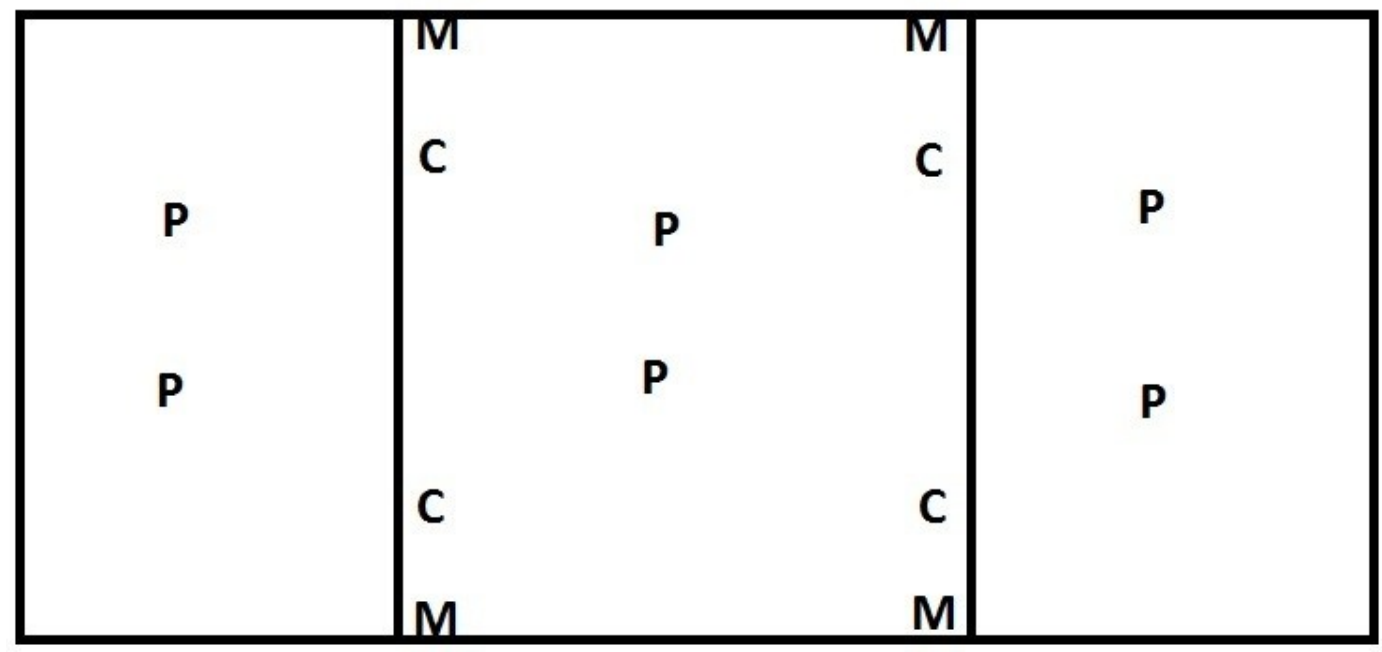

MÉTODO DE AVALIAÇÃO DE POPULAÇÃO DE CASCUDINHO (ALPHITOBIUS DIAPERINUS) PANZER EM AVIÁRIOS DE FRANGO DE CORTE.

LEGENDA: Ponto de amostragem da cama juntos aos pilares $(P)$, muretas $(M)$ e comedouros $(C)$ em aviário de frango de corte.

Fonte: Godinho, (2009, p. 108).

Repete-se o numero da amostragem no aviário, antes da saída do primeiro lote de aves, que foi uma semana antes da saída desse primeiro lote alojado, de forma que os dados obtidos na primeira amostragem corresponderão à totalidade da população (100\%), e a avaliação subsequente indicou o percentual de re-infestação no aviário e, consequentemente, relatou a eficiência da estratégia de controle do cascudinho aplicada no aviário. O método ainda possui a vantagem de permitir comparações, tanto da população do aviário todo ou de cada um dos locais amostrados como pilares, muretas e comedouros.

Com relação ao método, Alves et al. citado por Godinho (2009, p. 109) da a sua contribuição salientado que: 
Ressalta-se que este método vem sendo utilizado há cerca de seis anos, como prática rotineira de avaliação de eficiência de inseticidas químicos e recentemente foi adotado para avaliação de um produto à base de terra de diatomáceas.

O método realizado com a amostragem da cama, evidencia a vantagem de ser um método para estimar a população em termos absolutos, já que as amostras têm tamanho ou volume determinados e padronizados entre si.

Desta maneira, as vantagens do método são várias, devido ao fator que neste, foram analisados 14 pontos divididos em três localizações, sendo os pilares, muretas e comedouros, podem ser efetuadas inferências conforme a maior ou menor concentração de cascudinhos em cada uma dessas localizações. Assim, quando o aviário está em condições normais, sempre a maior concentração de cascudinhos será embaixo dos comedouros pelo fato de certa forma estarem protegidos de serem ingeridos pelas aves, e seriam localizados em baixas concentrações em muretas e pilares, geralmente com números parecidos entre os dois. Caso ocorra o aumento da população de cascudinhos dentro do aviário, implicará subsequentemente numa elevação do número de insetos sob os comedouros e consequentemente um aumento no número de cascudinhos nas muretas e quando há casos de superpopulação a quantidade de cascudinhos, conjuntamente aos pilares, estará visível.

Com relação ao número de indivíduos da primeira população, avaliada em toda a área do aviário, através do cálculo no quadro 1, evidenciou-se uma população de besouros Alphitobius diaperinus, com número de indivíduos adultos estimado em 8.768.333,33.

Na sequência o quadro 1, demonstrou as dimensões das áreas, ressaltando que as áreas : $1 ; 2 ; 13 ; 14$ possuem trezentos metros quadrados e as áreas :3, 4, 5, $6,12,9,10$ e 11,constituem áreas de cinquenta metros quadrados. $E$ as áreas 7 e 8 perfazem cada uma das referidas áreas, cem metros quadrados, assim sendo o aviário, possui quatro áreas que são mais amplas $(2,1,13$ e 14) que estão situadas na laterais , as outras dez áreas são menores e estão situadas no centro.

O referido cálculo, envolve o aviário em toda sua extensão, sendo que o mesmo foi dividido, para contagem de uma amostra medindo $30 \times 30 \mathrm{~cm}$, chegando à uma amostra de $900 \mathrm{~cm}^{2}$, que posteriormente foram convertidos por $\mathrm{m}^{2}$, em 14 pontos estratégicos. Assim, com a divisão e a contagem, pode-se através de cálculo estimar a população total de Alphitobius diaperinus adultos.

Ressaltando que na área de trezentos metros quadrados, com a amostra um de 375, totalizou uma população por área de 1.250.000,00 e na mesma área a amostra dois, com oitenta e sete totalizou uma população por área de 290.000,00. Para maior clareza com relação aos dados obtidos o quadro 1, evidencia o cálculo da população total do aviário, identificando as 14 áreas, com as amostras um e dois, constatando o total da população por área. 
Quadro 1 - Dimensões das áreas e Cálculo referente à população de Alphitobius diaperinus

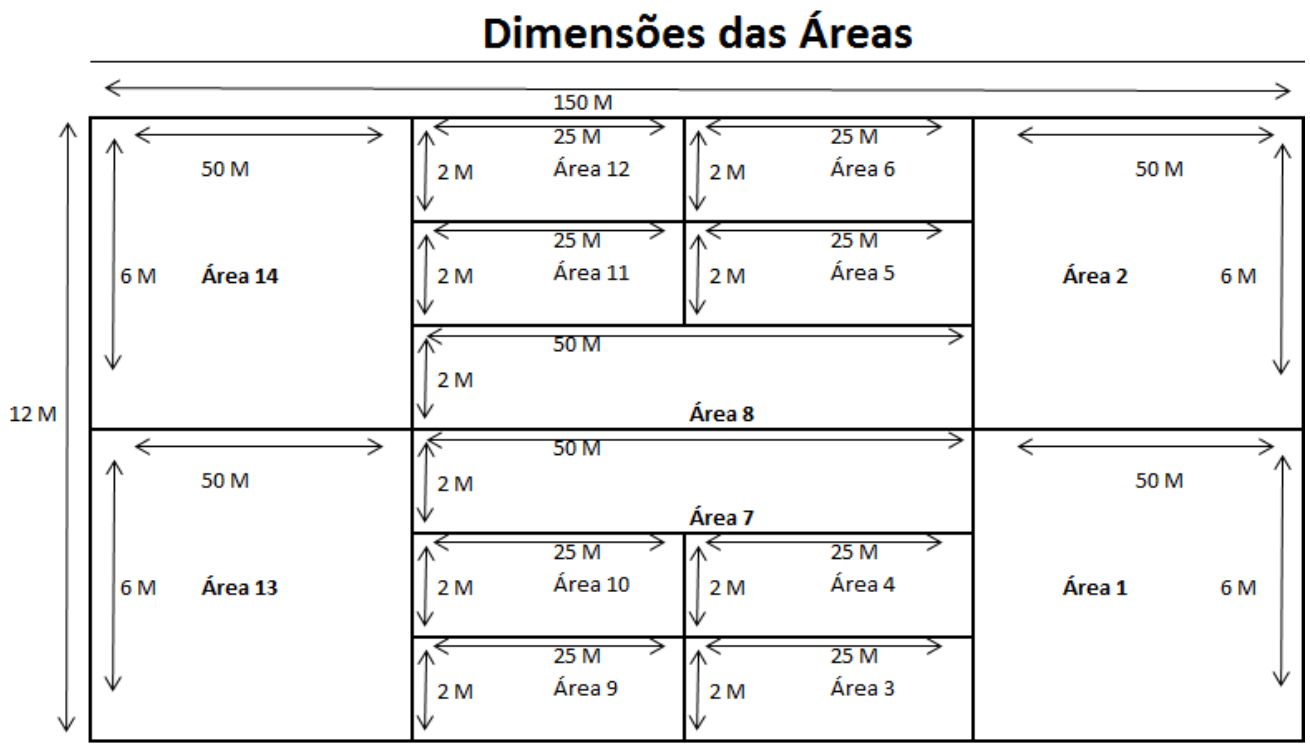

\begin{tabular}{|c|c|c|c|c|c|c|c|}
\hline \multicolumn{8}{|c|}{ Cálculo da população total do aviário } \\
\hline \multicolumn{8}{|c|}{$\begin{array}{l}\text { Área considerada de amostra de } 30 \mathrm{~cm} \times 30 \mathrm{~cm}^{900 \mathrm{~cm}^{2}} \\
\text { Fórmula: Total por } \mathrm{M}^{2}=\left((\text { População / } \mathbf{9 0 0})^{*} \mathbf{1 0 0 0 0}\right) \\
\text { Onde } 900 \mathrm{Cm}^{2} \text { é a Área da amostra } \\
\text { Onde } 10000 \text { é a conversão da população de } \mathrm{Cm}^{2} \text { para M² }\end{array}$} \\
\hline $\begin{array}{l}\text { Identifica } \\
\text { ção Área }\end{array}$ & $M^{2}$ da Área & Amostra 1 & Total Por $\mathbf{M}^{2}$ & \begin{tabular}{|l|}
$\begin{array}{l}\text { Total da } \\
\text { população } \\
\text { por Área }\end{array}$ \\
\end{tabular} & Amostra 2 & Total Por $\mathbf{M}^{2}$ & \begin{tabular}{|l|}
$\begin{array}{l}\text { Total da } \\
\text { população por } \\
\text { Área }\end{array}$ \\
\end{tabular} \\
\hline 1 & 300 & 375 & $4.166,67$ & $1.250 .000,00 \mid$ & 87 & 966,67 & $290.000,00$ \\
\hline 2 & 300 & 388 & $4.311,11$ & $1.293 .333,33$ & 83 & 922,22 & $276.666,67$ \\
\hline 3 & 50 & 1250 & $13.888,89$ & $694.444,44$ & 1276 & $14.177,78$ & $708.888,89$ \\
\hline 4 & 50 & 3275 & $36.388,89$ & $|1.819 .444,44|$ & 1987 & $22.077,78$ & $1.103 .888,89$ \\
\hline 5 & 50 & 3280 & $36.444,44$ & $1.822 .222,22 \mid$ & 1968 & $21.866,67$ & $1.093 .333,33$ \\
\hline 6 & 50 & 1188 & $13.200,00$ & $660.000,00$ & 1180 & $13.111,11$ & $655.555,56$ \\
\hline 7 & 100 & 118 & $1.311,11$ & $131.111,11$ & 25 & 277,78 & $27.777,78$ \\
\hline 8 & 100 & 111 & $1.233,33$ & $123.333,33$ & 18 & 200,00 & $20.000,00$ \\
\hline 9 & 50 & 67 & 744,44 & $37.222,22$ & 18 & 200,00 & $10.000,00$ \\
\hline 10 & 50 & 204 & $2.266,67$ & $113.333,33$ & 281 & $3.122,22$ & $156.111,11$ \\
\hline 11 & 50 & 198 & $2.200,00$ & $110.000,00$ & 271 & $3.011,11$ & $150.555,56$ \\
\hline 12 & 50 & 73 & 811,11 & $40.555,56$ & 12 & 133,33 & $6.666,67$ \\
\hline 13 & 300 & 98 & $1.088,89$ & $326.666,67$ & 18 & 200,00 & $60.000,00$ \\
\hline 14 & 300 & 104 & $1.155,56$ & $346.666,67$ & 22 & 244,44 & $73.333,33$ \\
\hline Total & 1800 & & & $8.768 .333,33$ & & & $4.632 .777,78$ \\
\hline
\end{tabular}

Fonte: Mendes (2013)

Saúde Meio Ambient. v. 6, n. 1, p. 107-122, jan./jun. 2017 
Como é relatado no quadro, o número de indivíduos da primeira população na área do aviário, avaliada em toda a área do aviário, através do cálculo evidenciou-se uma população de besouros Alphitobius diaperinus, com número elevado de indivíduos adultos estimado em 8.768.333,33.colocar valore aproximados no texto

Com relação a reinfestação de besouros Alphitobius diaperinus, calculada em toda a área do aviário no quadro 2 , evidenciou-se um total estimado de indivíduos adultos de Alphitobius diaperinus, de 4.632.777,78 indivíduos, evidenciando que após o controle, houve uma redução de mais da metade de indivíduos da população de cascudinhos em relação à primeira contagem, que era de aproximadamente 8.768.333,33 indivíduos.

Evidenciou-se que a população de cascudinhos é uma população alta em números de indivíduos adultos, devido às condições de sobrevivência que o aviário dispõe, incluídas nestas, alimento e condições ideais para reprodução. O controle da população de cascudinhos foi de extrema relevância, pois se o mesmo não for realizado corretamente, pode resultar em um aumento exagerado da população de cascudinhos, o que implica em diversos e sérios problemas para o lote de aves no aviário, com prejuízos financeiros ao proprietário.

\section{CONCLUSÃO}

O Alphitobius diaperinus ocasiona sérios problemas nas granjas avícolas, interferindo no desempenho de frangos, com prejuízos aos proprietários. Na referida pesquisa, que objetivou constatar os métodos para controle do Alphitobius diaperinus, constatou-se que a maior incidência de cascudinhos foi em uma área denominada pinteira, onde os frangos permanecem por mais tempo, desde $o$ início de seu ciclo. Sendo que esta, por estar sempre habitada pelas aves, apresenta maiores condições de vida para os cascudinhos, por dispor de mais alimento e temperaturas ideais para aumento de população.

Ressaltando também com relação ao controle realizado no aviário, os resultados indicaram bom potencial de controle da população de Alphito biusdiaperinus, o que evidenciou que o método de controle químico, é eficaz, pois a redução da população de Alphitobius diaperinus apresentou resultado significativo.

Assim sendo, está pesquisa foi de extrema relevância, pois a pesquisadora, vivenciou que os métodos de controle químicos e mecânicos, são procedimentos e atos que podem ser realizados pelo avicultor, para dificultar o desenvolvimento do cascudinho, para melhorar a carne das aves, que são destinadas para consumo humano. Considerando também que, quando se busca métodos eficientes, para o controle do cascudinho, por coerência deve-se contemplar métodos de avaliação e monitoramento que possibilitem avaliar sua eficácia em longa escala. Assim sendo, são necessários estudos mais aprofundados, na busca de métodos de controle, com outros princípios ativos não químicos, para melhoria da produção, considerando as questões ambientais. 


\section{REFERÊNCIAS}

ALVES, L.F.A. et al. Ação da terra de diatomácea contra adultos do cascudinho Alphitobius diaperinus(Panzer, 1797) (coleoptera: tenebrionidae). 2006. v.73. Comunicação Científica - Universidade Estadual do Oeste do Paraná, Cascavel, 2006. Disponível em: <www.biologico.sp.gov.brdocsarqV73_1alves.PDF>. Acesso em: 28 ago. 2012.

BERNIGAUD, I.C. et al. Controle do Alphitobius diaperinus em cama de frangos para grelhados com o produto Eco-Guard®. Instituto Nacional de Tecnología Agropecuaria, 20 out. 2011. Disponível em: <http://pt.engormix.com/MAavicultura/administracao/artigos/controle-alphitobius-diaperinus-cama-t658/124p0.htm>. Acesso em: 28 ago. 2012.

BORROR, Donald J. Introdução ao estudo dos insetos. São Paulo, SP: E. Blucher, 1969.

CHERNAKI, Andreia M.; ALMEIDA, Lúcia M. de. Exigências Térmicas, Período de Desenvolvimento e Sobrevivência de Imaturos de Alphitobius diaperinus (Panzer) (Coleoptera: Tenebrionidae). Ecology, Behavior and Bionomics, Curitiba - PR, v.30, n.3, p. 365-368, set. 2001. Disponível em:

<httpwww.scielo.brpdfnev30n3a04v30n3.pdf>. Acesso em: 11 set. 2012.

EMPRAPA. Centro Nacional de Pesquisa da Soja (Londrina, PR). A.M. ChernakiLeffer; D.R. Sosa-Gomez; L.M. de Almeida. Suscetibilidade de Alphitobius diaperinus (Panzer, 1797) (coleoptera: tenebrionidae) a reguladores de crescimento de insetos (RCI). v. 73, n. 1, p. 51-55, jan./mar., 2006. Disponível em: <http200.144.6.109docsarqV73_1leffer.PDF>. Acesso em: 5 abr. 2013.

GAZONI, F.L. et al. Avaliação da resistência do cascudinho (Alphitobius diaperinus) (Panzer) (coleoptera: tenebrionidae) a diferentes temperaturas. Arq. Inst. Biol., São Paulo, v. 79, n. 1, p. 69-74, jan./mar., 2012. Disponível em: <httpwww.biologico.sp.gov.brdocsarqv79_1gazoni.pdf>. Acesso em: 11 set. 2012.

GODINHO, R.P.; ALVES, L.F.A. método de avaliação de população de cascudinho (Alphitobius Diaperinus) Panzer em aviários de frango de corte. Arq. Inst. Biol, São Paulo, v. 76, n. 1, p. 107-110, jan./mar., 2009. Disponível em:

<http200.144.6.109docsarqv76_1godinho.pdf>. Acesso em: 05 abr. 2013.

GULLAN, P. J.; CRANSTON, P. S. Os insetos: um resumo de entomologia. 3. ed. São Paulo: Roca, 2008.

HICKMAN, Cleveland P. JR.; ROBERTS, Larry S.; LARSON, Allan. Princípios Integrados de Zoologia. 11.ed. Rio de Janeiro: Editora Guanabara Kooga 2004. 
HUEMURA, D.H. et al. Distribuição e dinâmica populacional do cascudinho Alphitobius diaperinus (Coleoptera: Tenebrionidae) em aviários de frango de corte. Arq. Inst. Biol., São Paulo, v.75, n.4, p.429-435, out./dez., 2008. Disponível em: <httpwww.biologico.sp.gov.brdocsarqv75_4uemura.pdf>. Acesso em: 11 set. 2012.

JAPP, Anne K.; BICHO, Carla de L.; SILVA, Ana V. F. da. Importância e medidas de controle para Alphitobius diaperinus em aviários. Ciência Rural, Santa Maria - RS, v.40, n.7, p. 1668-1673, jul, 2010. Disponível em:

<www.scielo.brpdfcrv40n7a652cr2412.pdf>. Acesso em: 28 ago. 2012.

MATIAS, R.S. Controle de Alphitobius diaperinus em piso e cama de aviários. Pesq. agropec. bras., Brasília, v.27, n.1, p. 205-207, jan. 1992. Disponível em:

$<$ httpsseer.sct.embrapa.brindex.phppabarticleview3636927>. Acesso em: 05 abr. 2013.

SILVA, Aleksandro Schaferda et al. Ciclo biológico do cascudinho Alphitobiusdia perinusem laboratório. Acta Scientiae Veterinariae, Santa Maria, março 2005. p.177-181. Disponível em: <httpwww.ufrgs.bractavet33-2artigo624.pdf>. Acesso em: 11 set. 2012.

SIMPÓSIO DE INOVAÇÃO TECNOLÓGICA, 2., 2010, Cascavel. Controle do cascudinho dos aviários Alphitobius diaperinus com fungo Beauveria bassiana em aviário de frango de corte. Cascavel, 2010. Disponível em:

$<$ httpprojetos.unioeste.brcampinitfilessitec2010resumosElisangela.pdf $>$. Acesso em: 11 set. 2012.

SIMPÓSIO SOBRE RESÍDUOS DA PRODUÇÃO AVÍCOLA, 2000, Concórdia. Controle de moscas e cascudinhos: desafios na produção agrícola. Concórdia, 2000. Disponível em: <httpdocsagencia.cnptia.embrapa.brsuino...anais65 pedrosodepaiva.pdf>. Acesso em: 28 ago. 2012.

TRIPLEHORN, Charles A.; JOHNSON, Normam F. Estudos dos insetos. São Paulo: Cengage Learning, 2011.

VITTORI, Juliano et al. Alphitobius diaperinus spp como veiculador de Clostridium perfringens em granjas avícolas do interior paulista - Brasil. Ciência Rural, Santa Maria - RS, v. 37 n. 3. jun, 2007. Disponível em: <www.scielo.br/scielo.php?script= sci_arttext\&pid=S0103>. Acesso em: 28 ago. 2012.

Artigo recebido em: 16/05/2014

Artigo aprovado em: 31/03/2016 